\title{
Does Adversity Make Us Wiser Than Before? Addressing a Foundational Question Through Interdisciplinary Engagement
}

\author{
Eranda Jayawickreme ${ }^{1} \cdot$ Stephen R. Grimm ${ }^{2} \cdot$ Laura E. R. Blackie $^{3}$
}

Published online: 7 September 2019

(C) Springer Nature B.V. 2019

Current perspectives on wisdom have often claimed that wisdom is a form of knowledge, but differ with respect to the virtues, skills, and abilities they believe characterize the wise person. Although there has been considerable theoretical interest in the topic of wisdom, there has been little empirical work examining the question of whether adversity can act as a catalyst for wisdom, and which wise virtues and skills are most likely to develop from experiencing adversity. This question was the focus of an interdisciplinary summer seminar at Fordham University in June 2017 led by the authors of this article. The present special issue is the result of the discussion at the seminar and focuses on some questions that future research should consider. For example, does adversity provide unique opportunities for insights that function as the catalysts for meaningful changes to an individual's personality, goals, and life priorities? What are the types of adversity that lead to wisdom; "major" life events such as significant trauma, more "minor" normative stressors, or perhaps the "minor" life events that must be confronted as a result of a "major" life event? Are these gains permanent or reversible? And if most people respond to adversity without significant personological changes, as some have argued (see Infurna \& Luthar, 2017 for a discussion of this literature), then to what extent does adversity in fact lead to wisdom?

These questions are in part a function of the intuitive resonance of people's beliefs about the instructive role adversity may play in shaping character, perhaps best captured by Nietzsche's (1889/1998) famous claim, “That which doesn't kill me makes me stronger". Indeed, embedded in this famous claim is the assertion that we do benefit from successfully overcoming adversity. Related research into post-traumatic growth-positive psychological change as a result of the struggle to overcome

Eranda Jayawickreme

jayawide@wfu.edu

1 Department of Psychology, Wake Forest University, 415 Greene Hall, P.O. Box 7778, Winston-Salem, NC 27109, USA

2 Fordham University, New York, NY, USA

3 University of Nottingham, Nottingham, UK 
highly challenging life circumstances-has shown that people report experiencing a greater appreciation of life, more-intimate social relationships, heightened feelings of personal strength, greater engagement with spiritual questions, and the recognition of new possibilities for their lives (Tedeschi \& Calhoun, 2004). Researchers have claimed that these changes reflect important qualities of character such as possessing a loving disposition, purposefulness, and humility (Jayawickreme \& Blackie, 2016), and reports of post-traumatic growth have been associated with lower levels of depression and higher levels of well-being (Helgeson, Reynolds, \& Tomich, 2006).

Some researchers have claimed that post-traumatic growth might be best represented in terms of meaningful changes in wisdom. In an early paper examining this link, Linley (2003) identified three dimensions highlighting the central role of wisdom as both a process and an outcome of positive adaptation to traumatic events (Jayawickreme \& Blackie, 2016). These dimensions include:

- Recognition and management of uncertainty in life (occurring through shattered schemas and positive adaptation in its wake, including openness to change)

- Integration of affect and cognition (individuals are aware but not "at the mercy of" their somatic sensations in facing up to life)

- Recognition and acceptance of human limitation (such as the tolerance of uncertainty given that we have limited knowledge and insight about the world; recognition of our limited lifespan)

It is worth noting that Linley's model relies on the basic assumption that adversity can shatter an individual's worldview (Janoff-Bulman, 1992), but to date there is little empirical evidence to support the notion that worldviews are "shattered" and need to be re-built before an individual may change and grow from their experience (Jayawickreme \& Blackie, 2014; Seery, Holman, \& Silver, 2010; Tennen \& Affleck, 2000). Additionally, the status of self-perceived retrospective reports of post-traumatic growth remains highly controversial (Ford, Tennen, \& Albert, 2008; Infurna \& Jayawickreme, 2019; Jayawickreme \& Blackie, 2014; Tennen \& Affleck, 2009). Given the lack of clarity over what self-perceived post-traumatic growth reports measure, the specific virtues, traits, and abilities that develop in response to different types of adversity remain unknown (Miller, 2014). One key question that should be the target of further investigation by religious scholars, philosophers, and psychologists is the extent to which adversity ultimately affords the development of wisdom (Jayawickreme \& Blackie, 2016; Tiberius, 2008). This special issue represents an important first step in answering this question.

\section{Wisdom Seminar at Fordham University}

In order to explore these questions from an interdisciplinary perspective, we organized an interdisciplinary summer seminar at Fordham University in June 2017. A group of philosophers, theologians, religious scholars, and psychologists discussed critical issues about the connection between different forms of 
adversity (ranging from everyday adversity to natural disaster, civil war, and genocide), and the different perspectives on wisdom provided in psychology and other disciplines. The goals of the seminar were at least threefold; 1) to stimulate interdisciplinary discussion that further develops new theoretical perspectives on wisdom; 2) to foster interdisciplinary collaboration on the topic of wisdom following adversity among researchers with shared interests and fresh perspectives, leading to new research endeavors on wisdom following adversity in psychology, philosophy, religious studies, theology, and other disciplines; and 3) provide a "deep integration" approach to the notion of post-traumatic wisdom in preparation for an integrative set of empirical projects. The goals of this seminar set it clearly apart from prior seminars on wisdom, such as the 2010 discussion on wisdom at the Rosewood Inn in Hastings, Minnesota, which led to the Rosewood Report on Wisdom.

The summer seminar was based at the Empire Hotel near the Fordham University campus in New York on June 14-16 2017. The following philosophers, theologians and psychologists participated in the seminar:

\section{Psychologists \\ Michel Ferrari \\ Bill Chopik \\ Igor Grossmann \\ Don Davis \\ Judith Glück \\ Howard Nusbaum \\ Robert McGrath \\ Monika Ardelt \\ Kate McLean \\ Tenelle Porter \\ Margaret Plews-Ogan}

\section{Theologians}

Will Kynes

Stephen Pope

Philosophers

Georgi Gardiner

Julia Staffel

Emily McRae

Eric Yang

Ian Kidd

Ursula Renz

Michael Brady

Jason Baehr

Paul O'Grady 
Over a series of talks and group discussions, we evaluated the following four questions (following Jayawickreme \& Blackie, 2016):

1. What are the core thought processes, skills, traits, virtues, and practices that characterize wisdom following adversity? (cf. Baehr, O'Grady in this issue \& McRae in vol. 52 (4))

2. What is the adaptive value of wisdom following adversity? Does it foster psychological "toughness" or psychological growth? (cf. Plews-Ogan \& Ardelt \& Owens this issue)

3. Is an increase in wisdom following adversity more likely for people who already have a necessary set of pre-existing attributes? What are those attributes? (cf. Baehr, this issue, McRae in vol. 52 (4), Glück, Bluck \& Weststrate, this issue \& Davis, this issue).

4. What experiences of adversity can "teach" wisdom that leads to pursuit of the "good" life? (cf. Kidd in vol. 52 (4) \& Kidd, Kynes, Blackie \& McLean in this issue)

The seminar produced seven papers by Baehr, Plews-Ogan and colleagues, Glück and colleagues, Davis, O'Grady, McRae, and Kidd, as well as seven interdisciplinary think pieces, which extend this discussion with novel interdisciplinary discussions of the link between wisdom and adversity. This special issue collects these papers together with the exception of those by McRae and Kidd, which were published in vol. 52 (4), 2018 of this journal due to an administrative error. However, the contributed papers are discussed both in this introduction and in an invited commentary by Robert Sternberg.

A number of the authors reflected on the first question: What are the core thought processes, skills, traits, virtues, and practices that characterize wisdom following adversity? This question was addressed in considerable depth by three authors in particular. Baehr, for example, first outlined a definition for wisdom before linking it to adversity and discussing how the possession of the virtue humility may facilitate the development of wisdom following adversity. According to Baehr, this first question of 'what is wisdom?' is defined in part by a set of putative features, including expertise, understanding, experience, advice, skill, judgment, self-knowledge, and virtue. McRae and O'Grady, however, address this question by drawing from one specific religious tradition or philosophical perspective. McRae's argument draws from the Mahayana Buddhist philosophy arguing that wisdom is a deep and integrated understanding of the way things are across three domains: the ultimate, the conventional, and the moral. O'Grady puts forward a definition of wisdom as a theoretical virtue developed from Aquinas, which he attempts to reconcile with other contemporary theories of wisdom across philosophical and psychological disciplines.

Given the conceptual focus of the seminar, all authors addressed the second question in their articles to some degree: What is the adaptive value of wisdom following adversity? Does it foster psychological "toughness" or psychological growth? However, the focus on the second part of this question was addressed most directly by Plews-Ogan, Ardelt, and Owens who empirically examined the relationship between perceived post-traumatic growth, wisdom, and specific character virtues, such as 
forgiveness, gratitude, and spirituality. They present empirical support for two theoretical models of wisdom, demonstrating that perceived post-traumatic growth after adversity facilitated both reports of wisdom and the aforementioned virtues of forgiveness, gratitude, and spirituality.

The majority of authors in this special issue addressed the third question: Is an increase in wisdom following adversity more likely for people who already have a necessary set of pre-existing attributes? What are those attributes? After defining wisdom as outlined earlier, Baehr provides a conceptual argument for why we should expect the possession of humility to increase a person's capacity for wisdom in the context of suffering. In other words, he argues that possessing humility should predict the development of wisdom following adversity. As part of this argument, Baehr provides an argument for a distinctive conception of wisdom. McRae argues that the Buddhist ethical framework of the six perfections provides a helpful way to understand why some individuals become wise in the face of adversity while others do not. The Six Perfections in Mahayana Buddhist ethics, on her view, are specifically designed to guide the transition from suffering and confusion to happiness and wisdom. She specifically focuses on the Perfections of enthusiasm and meditative concentration in her article as she argues that these attributes have received less scholarly attention in Western theories of wisdom. Glück, Bluck, and Weststrate provide the first empirical test of the MORE Life Experience Model to examine whether individuals' capacity for psychological attributes of Mastery, Openness, Reflectivity, and Emotional Regulation (i.e., empathy) are related to their levels of wisdom. In contrast, Davis takes a novel approach, proposing that the measurement of perfectionism could act as a proxy for wisdom. By using evidence from the existing literature, Davis demonstrates that individuals high in perfectionism are unlikely to benefit from adversity, calling into question the extent to which benefits, such as increases in wisdom, are expected or typical.

The last question of the seminar-What experiences of adversity can "teach" wisdom that leads to pursuit of the "good" life?-was addressed by Kidd. In an innovative and thoughtful piece, Kidd (2018) makes the case for discussions of adversity to be included in exemplarist narratives (which can play a significant role in character virtue development). Specifically, the inclusion of experiences of adversity into such narratives can increase admiration for the exemplar, enable more effective emulation, and affirm deep truths about the human condition. Kidd and colleagues in this issue further elaborate on this notion in an interdisciplinary thought piece, as described in the following paragraph. Finally, Sternberg (this issue) provides a very helpful overview of these papers, and outlines four distinct ways of conceptualizing wisdom-in terms of a property of a person, situation, person/situation interaction, or action. He further specifies five criteria for a theory of wise action derived from his balance theory of wisdom.

The seven thought-pieces published here represent the outcomes of interdisciplinary engagement that occurred during the Wisdom Seminar. Brady provides a brief precis of his broad argument for how suffering can promote virtue (see also Brady, 2018). Porter et al. argue for the unique role of humility as a key character virtue that develops in the wake of adversity, while Ardelt et al. highlight distinct contextual factors that may support wisdom development following adversity. Chopik et al., McGrath, and Ferrari et al. 
provide specific methodological recommendations for future research on the link between adversity and wisdom, while Kidd et al. provide specific steps for using narratives of adversity and wisdom in ancient ethical and spiritual texts in interventions to promote wisdom.

In conclusion, we believe that key theoretical and methodological challenges in the examination of the relationship between wisdom and adversity remain, and much work needs to be done by philosophers, theologians, and psychologists to clarify definitions of wisdom and distinguish between different types of adversity that are more or less likely to cultivate wisdom. Nevertheless, the articles and think-pieces generated by the Wisdom Seminar presented in this issue illustarte that theory-predicated and methodologically-sophisticated research that combines empirical rigor and interdisciplinary insights are gradually becoming the norm in this area of research. The Wisdom Seminar has made us optimistic that work by these authors and other young scholars can both advance understanding of whether and how adversity can lead to positive outcomes.

Acknowledgements This publication was made possible through the support of grant \#87 from the Templeton Religion Trust awarded to Jayawickreme \& Blackie. The opinions expressed in this publication are those of the authors and do not necessarily reflect the views of the Templeton Religion Trust.

\section{References}

Brady, M.S. 2018. Suffering and virtue. Oxford: Oxford University Press.

Ford, J.D., H. Tennen, and D. Albert. 2008. A contrarian view of growth following adversity. In Trauma recovery and growth: Positive psychological perspectives on posttraumatic stress, ed. S. Joseph and P.A. Linley, 297-324. Hoboken, NJ: Wiley.

Helgeson, V.S., K.A. Reynolds, and P.L. Tomich. 2006. A meta-analytic review of benefit finding and growth. Journal of Consulting and Clinical Psychology 74 (5): 797-816.

Infurna, F.J., and E. Jayawickreme. 2019. Fixing the growth illusion: New directions for research in resilience and post-traumatic growth. Current Directions in Psychological Science 28: 152-158.

Janoff-Bulman, R. 1992. Shattered assumptions: Towards a new psychology of trauma. New York: Free Press.

Jayawickreme, E., and L.E.R. Blackie. 2014. Post-traumatic growth as positive personality change: Evidence, controversies and future directions. European Journal of Personality 28: 312-331.

Jayawickreme, E., and L.E.R. Blackie. 2016. Exploring the psychological benefits of hardship: A critical reassessment of posttraumatic growth. Switzerland: Springer.

Kidd, I.J. 2018. Adversity, wisdom, and exemplarism. The Journal of Value Inquiry 52 (4): 379-393.

Infurna, F.J., and S.S. Luthar. 2017. The multidimensional nature of resilience to spousal loss. Journal of Personality and Social Psychology 112: 926-947.

McRae, E. 2018. Suffering and the six perfections: Using adversity to attain wisdom in Mahāyāna Buddhist ethics. The Journal of Value Inquiry 52 (4): 395-410.

Miller, C.B. 2014. A satisfactory definition of 'post-traumatic growth' still remains elusive. European Journal of Personality 28: 344-346.

Nietzsche, F. 1885/2003. Beyond good and evil. London: Penguin Press.

Seery, M.D., E.A. Holman, and R.C. Silver. 2010. Whatever does not kill us: Cumulative lifetime trauma, vulnerability, and resilience. Journal of Personality and Social Psychology 99: 1025-1041.

Tedeschi, R.G., and L.G. Calhoun. 2004. Posttraumatic growth: Conceptual foundations and empirical evidence. Psychological Inquiry 15: 1-18.

Tennen, H., and G. Affleck. 2009. Assessing positive life change: In search of meticulous methods. In Medical illness and positive life change: Can crisis lead to personal transformation?, ed. C.L. Park, S.C. Lechner, M.H. Antoni, and A.L. Stanton, 31-49. Washington, DC: American Psychological Association.

Tiberius, V. 2008. The reflective life: Living wisely with our limits. Oxford: Oxford University Press.

Publisher's Note Springer Nature remains neutral with regard to jurisdictional claims in published maps and institutional affiliations. 